\title{
O ENGENHEIRO DO AMANHÃ: A PROPOSIÇÃO DE UM FRAMEWORK CONCEITUAL NA PERSPECTIVA DA EDUCAÇÃO EMPREENDEDORA NO BRASIL
}

Elzo Aranha - eaaranha@ unifei.edu.br

Gabriel Viana Rennó - gabrielvianarenno@unifei.edu.br

Universidade Federal de Itajubá, Instituto de Engenharia de Produção e Gestão

Avenida BPS, $\mathrm{n}^{\mathrm{o}}$ 1303, bloco B - Pinheirinho

37500-903 - Itajubá - Minas Gerais

Resumo: Há mais de 20 anos que academia, indústria e Unesco constatam a crise no ensino de engenharia no Brasil, propondo soluções. Todos convergem que o Engenheiro do Amanhã no Brasil deverá possuir habilidades empreendedoras para que ele possa atuar neste contexto de constantes transformações da contemporaneidade. Um dos maiores desafios a serem superados para a realização do almejado é a formação do engenheiro hoje. Muitos cursos seguem os mesmos moldes do século passado, o que não contribui principalmente com o Weltanschauung, que é a habilidade de compreender e assimilar o mundo. Devido a essa defasagem no ensino de engenharia, muitos engenheiros não compreendem o conceito de globalização e não estão aptos a reagir e solucionar os problemas intrínsecos destes tempos. Desta forma, novas diretrizes das engenharias foram criadas para que haja uma resposta efetiva para essa crise. De modo a contemplar todos os fatores que se relacionam direta e indiretamente com e levar o entendimento ao Engenheiro do Amanhã, desenvolveu-se, após o levantamento teórico, um framework conceitual. O presente artigo provou-se inovador ao suprir duas lacunas na produção científica percebidas pelos autores e tem diversas implicações práticas para diversos públicos da academia.

Palavras-chave: Engenheiros no Futuro. Crise no Ensino de Engenharia. Educação Empreendedora. Novas Diretrizes. Engenharia no Brasil. 


\section{INTRODUÇÃO}

O novo perfil e a formação do engenheiro do amanhã é um dos temas que mais desperta o interesse de pesquisadores e professores da academia e profissionais da indústria (GALLOWAY, 2008; CONFEDERAÇÃO NACIONAL DA INDÚSTRIA, 2019). A análise da formação do engenheiro do amanhã deve ser desenvolvida à luz do cenário de diversas transformações desta última década (KOTLER, KARTAJAYA e SETIAWAN, 2017) e da existência da crise no ensino de engenharia que vem sido alertada pela própria Confederação Nacional da Indústria (CNI) há quase 15 anos (CONFEDERAÇÃO NACIONAL DA INDÚSTRIA, 2006, 2010, 2015, 2019).

Nas recorrentes constatações da existência de crise, destaca-se que o estudante de engenharia brasileiro gradua-se seguindo um modelo de formação desalinhado a este século (CONFEDERAÇÃO NACIONAL DA INDÚSTRIA, 2019). Esta formação desalinhada com as exigências das indústrias, organizações e sociedade do século XXI foi sinalizada pela Organização das Nações Unidas para Educação, Ciência e Cultura (UNESCO) (1998).

O cenário torna-se ainda mais desfavorável para o engenheiro em formação no Brasil ao se considerar as profundas transformações que ocorreram ainda neste final década do século XXI. Quando se trata de mercado, especialistas registram mudanças nos negócios para um cenário mais horizontal, inclusivo e social (KOTLER, KARTAJAYA e SETIAWAN, 2017). As indústrias, tanto internacional, quanto nacional, de acordo com Galloway (2008) e CNI (2019), convergem no axioma de que a educação dos futuros engenheiros deve estimular o desenvolvimento de competências para atuação dos mesmos no mundo que está em profundas transformações. A provocação levantada por Galloway (2008) e CNI (2019) sobre desenvolvimento de profissionais com competências para atuação em indústrias, empresas e outras organizações que se encontram em profundas transformações, não é recente. E tampouco é somente apontado pela indústria. Por exemplo, a UNESCO (1998) elencou o desenvolvimento de habilidades e iniciativas empreendedoras, como uma ação prioritária e uma das principais preocupações para o ensino superior para o século XXI.

Levantamentos preliminares da produção acadêmica brasileira de educação em engenharia apontam duas lacunas. A primeira lacuna trata-se da incipiente quantidade de artigos acadêmicos que procuram desenvolver conexões e ligações entre a formação do engenheiro do século XXI, desenvolvimento de habilidades empreendedoras e as atividades do pensamento da mais alta ordem e da mais baixa ordem, baseadas na Taxonomia de Bloom (BLOOM et al, 1956; KRATHWOHL, 2002). Esta lacuna aberta impede de compreender e entender como a educação empreendedora e os conceitos educacionais estabelecidos por Bloom (1956) podem contribuir para a formação do engenheiro do amanhã.

A segunda lacuna trata-se da incipiente quantidade de artigos que desenvolvem análises integradas das novas Diretrizes Curriculares Nacionais dos Cursos de Engenharia (DCNs) na perspectiva da educação empreendedora.

Diante deste pano de fundo que delineia os principais fatores que marcam as grandes transformações na sociedade do século XXI, a formação do engenheiro baseada na educação empreendedora é um dos requisitos essenciais. Nesta direção, emergem as seguintes questões: que framework conceitual é capaz de ampliar a compreensão e entendimento do Engenheiro do Amanhã sob uma perspectiva empreendedora e dos principais fatores que se relacionam entre si? $O$ presente artigo pretende preencher as duas lacunas existentes na produção acadêmica brasileira no campo da educação em engenharia. 
O objetivo do presente artigo é propor um framework conceitual que contribua para aumentar a compreensão e o entendimento da formação do engenheiro do amanhã na perspectiva da educação empreendedora que sintetize todo o levantamento teórico.

O presente artigo divide-se em quatro seções, não considerando a introdução, sendo a primeira sobre o momento atual, contextualizando a recomendação da UNESCO para o século $\mathrm{XXI}$, as mudanças no cenário dos negócios e as provocações da Indústria. A segunda trata das novas DCNs, as habilidades empreendedoras e a taxonomia de Bloom. A terceira apresenta o framework conceitual do Engenheiro do Amanhã numa perspectiva empreendedora. A quarta, por fim, conclui-se sobre a relevância e a inovação do artigo.

\section{O ENGENHEIRO HOJE}

Em sua Conferência Mundial sobre Educação Superior de 1998, a Organização das Nações Unidas para Educação, Ciência e Cultura (UNESCO) estabeleceu diversas ações para o ensino superior para o século XXI. Entre as diversas pautas, o desenvolvimento de habilidades e iniciativas empreendedoras foi considerada como uma ação prioritária e uma das principais preocupações para o ensino superior do próximo século, a fim de facilitar a empregabilidade dos graduados e, também, a criação de empregos pelos próprios graduados com seus empreendimentos.

Ora, se um novo milênio se aproxima, com novos desafios, os engenheiros terão de desenvolver soluções para lidar com os problemas desse "novo mundo". Porém, de acordo com o levantamento da literatura, esses profissionais demonstram não entender completamente tanto o conceito de globalização, como também não possuir uma compreensão ampliada dos problemas enfrentados pelos próprios engenheiros do século XXI. Observa-se também que carecem das competências que lhes permitiriam assumir posições de liderança no governo e na indústria (GALLOWAY, 2008).

O século que recebera as recomendações da UNESCO começava. Nele, Downing (2004) registrava mudanças culturais e midiáticas que já começavam a ser percebidas. As mídias alternativas começavam a ameaçar a hegemonia da cultura de massa. Percebia-se uma certa rebeldia dentro nas formas de comunicação e dos movimentos sociais, em uma forma disruptiva, contra códigos hegemônicos.

No campo da engenharia, uma transformação apontada foi a necessidade de engenheiros empreendedores capazes de não só resolver problemas, como perceber o problema que precisa ser resolvido. O perfil empreendedor do engenheiro foi defendido e considerado essencial pela CNI (CONFEDERAÇÃO NACIONAL DA INDÚSTRIA, 2006). Já em um aspecto macro de negócios, mais próximo do fim da segunda década, um dos maiores especialistas de economia comportamental e marketing, Kotler juntamente com os autores Kartajaya e Setiawan dissecaram os muito recentes fenômenos e acontecimentos. Kotler, Kartajaya e Setiawan (2017) listaram três profundas transformações no mercado mais relevantes, sendo elas expostas no Quadro 1.

Quadro 1 - As mudanças no campo dos negócios

\begin{tabular}{|c|c|c|}
\cline { 2 - 4 } \multicolumn{1}{c|}{} & Mudanças & Definição \\
\hline (1) & $\begin{array}{c}\text { De exclusivo } \\
\text { para inclusivo } \\
\text { está automatizada e se minituaturizando, reduzindo o custo dos produtos } \\
\text { (principalmente para atender mercados emergentes). A inclusão social e } \\
\text { o convívio com as diferenças estão sendo adotados pelas pessoas. As } \\
\text { mídias sociais promovem colaborações globais em inovação. }\end{array}$ \\
\hline
\end{tabular}


(C) COBENGE

"Os desafios para formar hoje o engenheiro do amanhã"

\begin{tabular}{|c|c|c|c|} 
(2) & $\begin{array}{c}\text { De vertical } \\
\text { para } \\
\text { horizontal }\end{array}$ & $\begin{array}{c}\text { Mercado extremamente competitivo. Pesquisa e desenvolvimento torna- } \\
\text { se inviável, devido aos robustos investimentos internos em inovação, e se } \\
\text { tornam-se Conexão e Desenvolvimento, para captação de inovação de } \\
\text { fontes externas em um ritmo mais acelerado para acompanhar as } \\
\text { inovações do mercado. }\end{array}$ \\
\hline (3) & $\begin{array}{c}\text { De individual } \\
\text { para social }\end{array}$ & $\begin{array}{c}\text { O conformismo social passa a ter um peso mais negativo. Os } \\
\text { consumidores valorizam mais as opiniões de um dos outros e } \\
\text { comunicam-se entre si sobre marcas e empresas tanto online quanto off- } \\
\text { line. }\end{array}$ \\
\hline
\end{tabular}

Fonte: adaptado de Kotler, Kartajaya e Setiawan (2017)

O que Downing (2004) começava a relatar no começo do século, fora registrado por Kotler, Kartajaya e Setiawan (2017) como mudanças já estabelecidas, confirmando-se, como por exemplo, o enfraquecimento de organizações hegemônicas de poder (mudança 1) e as mudanças nos meios de comunicação (mudança 3), vide Quadro 1.

Analisando o século do novo milênio, observa-se que o mundo constitui-se na civilização mais saudável, segura e produtiva da história. Toda a velocidade do progresso desafia fundamentalmente a maneira como a engenharia é praticada e a maneira como os estudantes de engenharia são educados (GALLOWAY, 2008). Assim sendo, os vínculos entre mundo do trabalho e a formação no ensino superior deveriam ser fortalecidos, sobretudo em países menos desenvolvidos. Ademais, seria necessária uma ação internacional para ajudar a estabelecer compromissos conjuntos entre o ensino superior e a indústria nesses países. (UNESCO, 1998).

Desta forma, a Confederação Nacional da Indústria (CNI), desde a primeira década do século XXI, expõe uma crise que então acentuava-se no ensino de engenharia no Brasil, gerando diversas provocações à discussão para o tópico (CONFEDERAÇÃO NACIONAL DA INDÚSTRIA, 2006, 2010, 2015, 2019).

Em 2006, a CNI alertou sobre a necessidade da reformulação do ensino de engenharia. Dentre as diversas raízes dessa necessidade, uma delas é a alta oferta de novos cursos de engenharia no país no começo do século. Entre 1997 e 2005, a média era de 78 novos cursos de engenharia por ano. Em 1996, existiam 545 cursos; em 2005, já eram 1.251 cursos. De acordo com a CNI, sem um controle de qualidade e sem planejamento, os novos cursos surgiam apenas à mercê do mapa de desenvolvimento socioeconômico e industrial do País. Sublinhou-se ainda a necessidade de engenheiros empreendedores (CONFEDERAÇÃO NACIONAL DA INDÚSTRIA, 2006).

No relatório de 2010, define-se uma relação interdependente entre inovação e empreendedorismo. Identifica-se também em casos de sucesso de bases educacionais um comportamento empreendedor muito forte (CONFEDERAÇÃO NACIONAL DA INDÚSTRIA, 2010). Em 2015, ainda mais incisiva, a organização trata como uma tendência mundial formar engenheiros com visão inovadora e empreendedora, afirmando que poucos cursos no Brasil a seguem (CONFEDERAÇÃO NACIONAL DA INDÚSTRIA, 2015).

Quase no final da segunda década, a CNI ainda apontava para a mesma crise - outrora exposta em 2006, 2010 e 2015, como visto - classificando como inadequada a prática de formar engenheiros no século XXI aos moldes do século XX. Ademais, estabelece-se que a formação dos estudantes requer a inclusão de elementos de estímulo à criatividade e à atitude empreendedora. Pontua-se também a necessidade de estimular competências para a atuação num mundo em profunda transformação tecnológica pela revolução digital (CONFEDERAÇÃO NACIONAL DA INDÚSTRIA, 2019).

Já datam quase 15 anos as provocações feitas pela Confederação Nacional da Indústria (CNI), que apontam o descompasso dos planos de trabalho das escolas de engenharia das universidades brasileiras e abrem possibilidades de análises em diversas direções (ARANHA 
e SANTOS, 2016; ARANHA e ARAÚJO, 2018). Retomando, a preocupação quanto ao desenvolvimento da inovação e ao fomento do empreendedorismo não é exclusiva da academia, mas também da indústria e da UNESCO. Desta forma, o Engenheiro do Amanhã, visado por estes órgãos, desenvolve inovações com suas diversas habilidades empreendedoras, inspirado pelas transformações e necessidades deste século.

\section{O ENGENHEIRO DO AMANHÃ}

Em resposta ao cenário previamente exposto, estabeleceram-se em 2019 as novas Diretrizes Curriculares Nacionais do Curso de Graduação em Engenharia (DCNs de Engenharia), fruto do debate junto aos órgãos de representação profissional, acadêmica e industrial, tais como o Conselho Federal de Engenharia e Agronomia (Confea), a Associação Brasileira de Educação em Engenharia (Abenge) e a Confederação Nacional da Indústria (CNI), visando atender as demandas futuras por mais e melhores engenheiros (BRASIL, 2019a).

Porém, antes que seja feita a análise das novas diretrizes, necessita-se conhecer em profundidade as habilidades empreendedoras, já que percebe-se o intrínseco relacionamento do Engenheiro do Amanhã com as mesmas. Na literatura, elas podem ser encontradas com seus diversos sinônimos. Por Gibb (2002) são chamadas de capacidades e por Filion (1993) de habilidades empreendedoras. A última forma citada será a mais adotada neste estudo. Desenvolver habilidades empreendedoras nos estudantes de engenharia é essencial, pois uma vez empregados em uma sociedade pós-moderna, os profissionais de engenharia não devem ter apenas capacidades técnicas, mas também habilidades empreendedoras, entre as quais visão, liderança, energia, saber ouvir e argumentar, networking, capacidade de resolução de problemas e de inovar, saber trabalhar em equipe e domínio de outros idiomas (FILION, 1993; GIBB, 2002; CONFEDERAÇÃO NACIONAL DA INDÚSTRIA, 2006, 2010, 2015).

Em Filion (1993), as habilidades tiveram um suporte conceitual muito sólido, baseandose no processo de desenvolvimento da visão do empreendedor, através de um Metamodelo. Dinamicamente, outros quatro fatores contribuem para o desenvolvimento da visão, como: as relações, a liderança, a energia investida e as percepções de mundo (Weltanschauung). Logo, temos cinco habilidades empreendedoras a serem desenvolvidas, que se relacionam entre si, dentro do Metamodelo de Filion, sendo elas expostas no Quadro 2.

Quadro 2 - As habilidades empreendedoras do Metamodelo de Filion

\begin{tabular}{|c|c|c|}
\hline (1) & Visão & $\begin{array}{c}\text { Projetar no futuro o lugar que o } \\
\text { empreendedor deseja que seu produto ou } \\
\text { seu projeto de carreira se desenvolva }\end{array}$ \\
\hline$(2)$ & Relaçães & $\begin{array}{c}\text { Relacionar-se com a finalidade de } \\
\text { desenvolver suas visões complementares }\end{array}$ \\
\hline$(3)$ & Liderança & $\begin{array}{c}\text { Desejar a realização da visão, de modo que } \\
\text { "tome as rédeas" da execução }\end{array}$ \\
\hline$(4)$ & Energia & $\begin{array}{c}\text { Alocar tempo e intensidade em atividades } \\
\text { que necessitam execução }\end{array}$ \\
\hline$(5)$ & Weltanschauung $(\boldsymbol{W})$ & $\begin{array}{c}\text { Transformar os estímulos da realidade, dos } \\
\text { seus valores, das memórias, do contexto } \\
\text { para gerar compreensão e percepção de } \\
\text { mundo, que constantemente reformula-se. }\end{array}$ \\
\hline
\end{tabular}

Fonte: Adaptado de Filion (1993)

Desta forma, a já exposta necessidade dos engenheiros do século XXI de não estarem alheios às profundas transformações atuais (GALLOWAY, 2008; CONFEDERAÇÃO NACIONAL DA INDÚSTRIA, 2019) está diretamente relacionada ao desenvolvimento da 
visão empreendedora nos engenheiros, pois trata-se da habilidade de Weltanschauung (W), ou seja, o prisma que o indivíduo enxerga o mundo real (FILION, 1993). Logo, se a formação do engenheiro atualmente desconsidera o contexto atual do século XXI e de sua segunda década, sua visão de mundo (W) estará comprometida.

As ferramentas utilizadas para desenvolver habilidades empreendedoras num contexto pedagógico podem ter sua eficácia analisada através da Taxonomia de Bloom. De acordo com Krathwohl (2002), a Taxonomia de Bloom é uma estrutura de classificação do que se é esperado que os alunos aprendam como resultado da instrução. Nesta estrutura, os domínios cognitivos são hierarquizados para que haja uma organização dos mesmos (como ilustra e esquematiza a Figura 1), através de dois grupos, sendo eles: (1) Atividades do Pensamento da Mais Baixa Ordem: que envolve três domínios cognitivos de menor abstração cognitiva (Conhecimento, Entendimento e Aplicação); e (2) Atividades do Pensamento da Mais Alta Ordem: que apresenta três domínios cognitivos de maior abstração cognitiva (Análise, Avalição e Criação). Confira a Figura 1.

Figura 1 - Domínios cognitivos na Taxonomia de Bloom

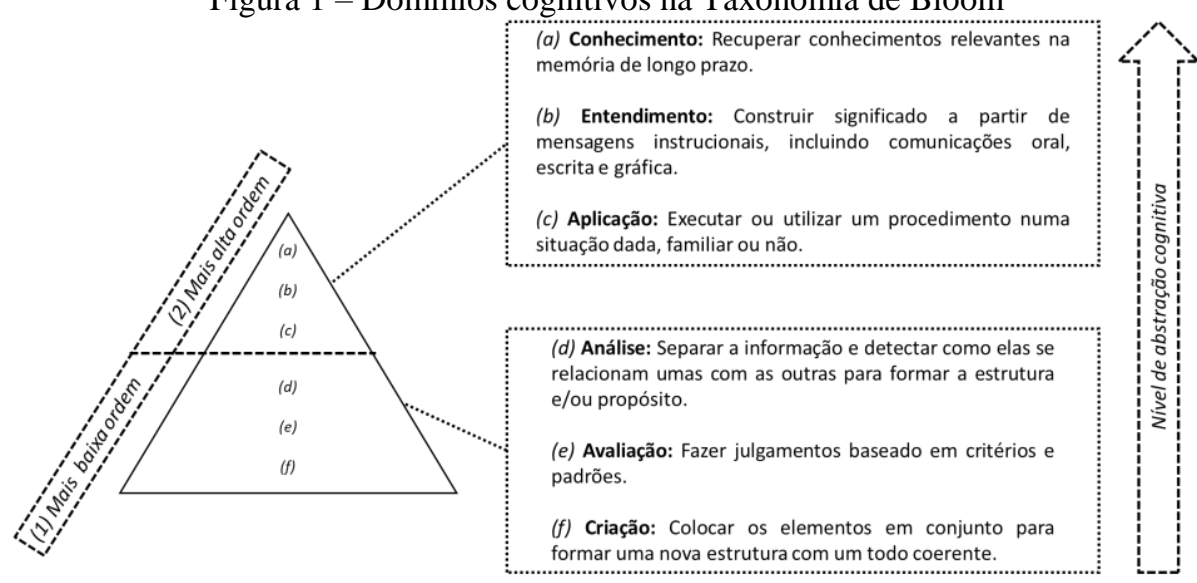

Fonte: Adaptado de Krathwohl (2002) e Aranha e Santos (2016)

De acordo com Aranha e Santos (2016), com a adoção da Taxonomia de Bloom durante o processo de aprendizagem, as atividades do pensamento estimuladas no estudante são verificadas através de uma espécie de feedback dos alunos, em relação à atividade da mente que vem sendo estimulada. Através do confronto entre a expectativa do professor e o feedback do aluno do que fora de fato estimulado, essa ferramenta pode gerar um replanejamento de uma estratégia de aprendizado, onde rastreia-se o que realmente tem funcionado e o que precisa ser melhorado. Como exemplos de ferramentas integradas empreendedoras que façam o citado estão a HONEE e a EDLE (ARANHA e SANTOS, 2016; ARANHA e ARAUJO, 2018).

Nesse sentido, as novas DCNs contemplam o exposto, no desenvolvimento de habilidades empreendedoras (FILION, 1993) e, indiretamente, no acompanhamento e na avaliação através da Taxonomia de Bloom (KRATHWOHL, 2002), pois, as competências serão desenvolvidas em graus de profundidade e complexidade crescentes ao longo do percurso formativo. Desta forma, para que os estudantes não apenas acumulem conhecimentos, mas que busquem, integrem, criem e produzam (vide domínios cognitivos na Figura 1) a partir de sua evolução no curso. Sendo ainda mais enfáticas, as diretrizes estabelecem que a formação do perfil do egresso deverá ser planejada e vista como um processo que exige o acompanhamento e a avaliação contínua, por meio de metodologias de avaliação que auxiliem na identificação de obstáculos e estratégias para superá-los, tornando 
assim a Taxonomia de Bloom, uma poderosa ferramenta, pois contempla todos estes requisitos (BRASIL, 2019a).

Através do Capítulo II das novas DCNs, tratam-se o perfil e as competências esperadas do egresso (BRASIL, 2019b). Nele, diversos trechos fazem a ligação com as habilidades empreendedoras de Filion (1993), dentre os trechos sendo os mais explícitos:

(1) Visão: "conceber, projetar e analisar sistemas, produtos (bens e serviços), componentes ou processos" (BRASIL, 2019b, Art. 4, III);

(2) Relações: "(...)interagir com as diferentes culturas, mediante o trabalho em equipes presenciais ou a distância, de modo que facilite a construção coletiva" (BRASIL, 2019b, Art. 4, VI, a);

(3) Liderança: "preparar-se para liderar empreendimentos em todos os seus aspectos de produção, de finanças, de pessoal e de mercado" (BRASIL, 2019b, Art. 4, VI, e);

(4) Energia: "implantar, supervisionar e controlar as soluções de Engenharia" (BRASIL, 2019b, Art. 4, IV).

(5) Weltanschauung $(W)$ : "ter visão holística e humanista, ser crítico, reflexivo, criativo, cooperativo e ético e com forte formação técnica” (BRASIL, 2019b, Art. $3, \mathrm{I})$;

Observa-se, desta forma, que o texto das novas diretrizes contempla todas as habilidades empreendedoras listadas por Filion (1993). Percebe-se também que a habilidade mais realçada é a W, confirmando o que fora exposto anteriormente sobre a necessidade dos engenheiros de não estarem alheios às transformações deste século (GALLOWAY, 2008; CONFEDERAÇÃO NACIONAL DA INDÚSTRIA, 2019; BRASIL, 2019b).

\section{4 \\ O FRAMEWORK DO ENGENHEIRO DO AMANHÃ NUMA PERSPECTIVA EMPREENDEDORA}

O framework (Figura 2) representa a distância e a ruptura nas relações entre o engenheiro atual com as profundas transformações do século, como o cenário negócios mais horizontal, inclusivo e social.

Figura 2 - Framework conceitual do Engenheiro do Amanhã numa perspectiva empreendedora
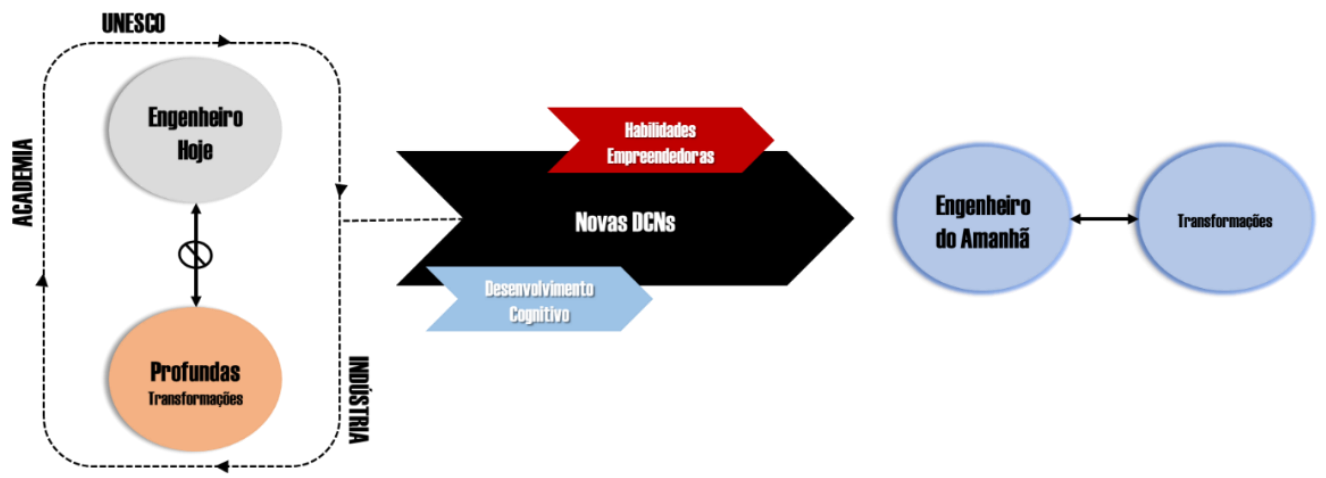

Fonte: Os autores

Enquanto as profundas transformações geram estímulos à mudança no perfil do engenheiro e na engenharia, ele e sua formação estão alheios a elas e, por isso, o engenheiro, com sua formação hoje, não sabe como e não possui habilidades para reagir na solução dos problemas da sociedade contemporânea. A academia, a indústria e a UNESCO debruçam-se sobre esse problema e propõe soluções há mais de 20 anos, antes mesmo da virada para este 
milênio (UNESCO, 1998; GALLOWAY, 2008; KOTLER, KARTAJAYA e SETIAWAN, 2017; CONFEDERAÇÃO NACIONAL DA INDÚSTRIA, 2019). Numa resposta à presente crise, em 2019, as novas diretrizes foram estabelecidas buscando um alinhamento do engenheiro do amanhã com as transformações futuras, para que haja uma efetiva ação do engenheiro na solução de problemas e que ele possua as habilidades necessárias para que o almejado seja concretizado. As novas DCNs buscam desenvolver habilidades empreendedoras e, ao mesmo tempo, acompanhando e a avaliando continuamente, por meio de metodologias como a Taxonomia de Bloom, no que tange o desenvolvimento dos domínios cognitivos (FILION, 1993; KRATHWOHL, 2002; GALLOWAY, 2008; BRASIL, 2019a, 2019b).

\section{CONSIDERAÇÕES FINAIS}

$\mathrm{O}$ presente artigo traz luz à pergunta na introdução. $\mathrm{O}$ framework conceitual proposto consegue ampliar a compreensão e o entendimento sobre o Engenheiro do Amanhã, que deverá ter seus elos de relacionamento reestabelecidos com transformações inerentes à contemporaneidade. O Engenheiro do Amanhã deverá compreender e reagir a essas mudanças.

O framework conceitual é inovador na produção acadêmica brasileira do campo da educação em engenharia. Primeiro porque contribuir para preencher as duas lacunas identificadas na produção científica. Segundo, aumenta a compreensão das conexões entre o engenheiro do amanhã com o desenvolvimento de habilidades empreendedora e Taxonomia de Bloom, que classifica e organiza os domínios cognitivos (BLOOM et al, 1956; KRATHWOHL, 2002). Terceiro, amplia a compreensão de forma integrada as novas DCNs (Diretrizes Curriculares Nacionais para o Curso de Engenharia) na perspectiva empreendedora.

A proposta de framework tem diversas implicações práticas, destacando-se duas. Primeiro, o framework pode fomentar em professores e pesquisadores da Educação Superior o desenvolvimento de novas metodologias para formação do Engenheiro do Amanhã. Segundo coordenadores de cursos, diretores de faculdades e universidades que ofertam cursos superiores com formação em engenharia pode mitigar mudanças no plano pedagógico e na realização de seminários para realizar a reflexão nos alunos e na comunidade em geral.

\section{REFERÊNCIAS}

ARANHA, E. A.; ARAÚJO, L. G. P. HONEE: Uma ferramenta de Educação Empreendedora aplicada em Engenharia. In: VII Congresso Brasileiro de Engenharia de Produção. Ponta Grossa. 2018. 12P. Disponível em: <http://aprepro.org.br/conbrepro/2018/down.php?id=5055\&q=1>. Acessado em: 15 abr. 2020

ARANHA, E. A.; SANTOS, P. H. A Formação do Engenheiro no Brasil: Provocações da Indústria e Proposições da Academia. In: XLIV Congresso Brasileiro De Educação Em Engenharia. $\quad 2016 . \quad$ Natal. 10P. Disponível em: <http://www.abenge.org.br/cobenge/arquivos/3/anais/anais/161073.pdf>. Acessado em: 15 abr. 2020

BLOOM, B.S., ENGELHART, M.D., FURST, E.J., HILL,W.H., \& KRATHWOHL, D.R. Taxonomy of education objectives: The classification of education goals. Handbook 1: Cognitive domain. New York: David McKay, 1956. 
"Os desafios para formar hoje o engenheiro do amanhã"

BRASIL. Conselho Nacional de Educação. Parecer CNE/CES N: 1/2019, de 23 janeiro de 2019. Diário Oficial da União, Brasília, DF, p. 109, 23 abr. 2019a. Seção 1.

BRASIL. Ministério da Educação. Conselho Nacional de Educação. Câmara de Educação Superior. Resolução $\mathbf{n}^{\mathbf{0}} \mathbf{2}$, de 24 de abril de 2019. Institui as Diretrizes Curriculares Nacionais do Curso de Graduação em Engenharia. 2019b. Brasília: Ministério da Educação, 2019.

Disponível

em: <http://portal.mec.gov.br/index.php?\%20option=com_docman\&view=download\&alias $=1126$ 81-rces002-19\&category_slug=\%20abril2019-pdf\&Itemid=30192>. Acessado em: 20 abr. 2020.

CONFEDERAÇÃO NACIONAL DA INDÚSTRIA. Destaques da MEI: Boas Práticas de Parceria Universidade-Empresa em Cursos de Graduação Em Engenharia. 2019. Disponível em: <https://bucket-gw-cni-static-cmssi.s3.amazonaws.com/media/filer_public/56/19/561909e7-31c6-408c-8da1-

d3b020b8f344/destaques_da_mei_boas_praticas_spread.pdf>. Acessado em: 15 abril 2020.

CONFEDERAÇÃO NACIONAL DA INDÚSTRIA. Engenharia para o Desenvolvimento: Inovação, Sustentabilidade e Responsabilidade Social como Novos Paradigmas. 2010. Disponível em: <http://bibliotecadigital.puc-campinas.edu.br/services/ebooks/ENG_DESENV_FINAL_WEB\%25203.pdf>. Acessado em: 15 abril 2020.

CONFEDERAÇÃO NACIONAL DA INDÚSTRIA. Fortalecimento das Engenharias. 2015. Disponível em: <https://bucket-gw-cni-static-cmssi.s3.amazonaws.com/media/filer_public/d5/e6/d5e67790-1274-4f4c-a0acc5611f300c4b/fortalecimentodasengenharias_web2.pdf>. Acessado em: 15 abril 2020.

CONFEDERAÇÃO NACIONAL DA INDÚSTRIA. Inova Engenharia: Propostas para a Modernização da Educação em Engenharia no Brasil. 2006. Disponível em: $<$ https://bucket-gw-cni-static-cms-si.s3.amazonaws.com/media/filer_public/c1/83/c18386c3bddb-4628-af1b-ce7d9eea5e54/20120709144801570711e.pdf >. Acessado em: 15 abril 2020.

DOWNING, John DH. Mídia radical: rebeldia nas comunicações e movimentos sociais. Senac, 2002.

FILION, Louis Jacques. Visão e relações: elementos para um metamodelo empreendedor. Revista de Administração de Empresas, v. 33, n. 6, p. 50-61, 1993. Disponível em: <https://www.scielo.br/pdf/rae/v33n6/a06v33n6.pdf>. Acessado em: 20 abr. 2020.

GALLOWAY, Patricia D. The 21st-century engineer: A proposal for engineering education reform. American Society for Engineering Education, 2008.

GIBB, A. In pursuit of a new 'enterprise' and 'entrepreneurship' paradigm for learning: creative destruction, new values, new ways of doing things and new combinations of knowledge. International Journal of Management Reviews. 2002. pp. 233-269.

KOTLER, Philip; KARTAJAYA, Hermawan; SETIAWAN, Iwan. Marketing 4.0: do tradicional ao digital. Sextante, 2017. 
"Os desafios para formar hoje o engenheiro do amanhã"

KRATHWOHL, D. R. A Revision of Bloom's Taxonomy: an overview. The Ohio State University. 2002. Disponível em: 〈https://www.depauw.edu/files/resources/krathwohl.pdf >. Acessado em: 11 abril 2020.

UNITED NATIONS EDUCATIONAL, SCIENTIFIC AND CULTURAL ORGANIZATION. World Declaration on Higher Education for the Twenty-first Century: Vision and Action and Framework for Priority Action for Change and Development in Higher Education adopted by the World Conference on Higher Education Higher Education in the Twenty-First Century: Vision and Action, 1998. Disponível em: <https://unesdoc.unesco.org/ark:/48223/pf0000141952>. Acessado em 18 abril 2020.

\title{
TOMORROW'S ENGINEER: A PROPOSITION OF A CONCEPTUAL FRAMEWORK FROM THE ENTREPRENEURIAL EDUCATION PERSPECTIVE IN BRAZIL
}

\begin{abstract}
For more than 20 years, academy, industry and Unesco have been witnessing the crisis in engineering education in Brazil, proposing solutions. All of them converge that the Engineer of Tomorrow in Brazil must have entrepreneurial skills so that he can act in this context of constant transformations of contemporary times. One of the biggest challenges to be overcome to achieve the desired goal is the guidelines for engineering education today. Many courses follow the same molds as the last century, which does not contribute mainly to Weltanschauung, which is the ability to understand and assimilate the world. Due to this gap in engineering education, many engineers do not understand the concept of globalization and are not able to react and solve the intrinsic problems of these times. In this way, new engineering guidelines were created in Brazil to effectively response to this crisis. In order to contemplate all the factors that are directly and indirectly related to and take the understanding to the Engineer of Tomorrow, a conceptual framework was developed after the theoretical basis. This article proved to be innovative in filling two gaps in scientific production perceived by the authors and has several practical implications for different audiences in academy.
\end{abstract}

Keywords: Engineers in the Future. Crisis in Engineering Education. Entrepreneurial Education. New Guidelines. Engineering in Brazil. 